\title{
Da natureza da pausa
}

Guido Imaguire*

Universidade Federal do Rio de Janeiro

\section{Resumo:}

Neste artigo eu analiso a noção de pausa musical de um ponto de vista filosófico. A principal dificuldade nesta análise diz respeito a sua aparente vacuidade ontológica: uma pausa parece não ser uma entidade que existe positivamente, mas a mera ausência de ser. Assim, nossa estratégia básica será a analogia com outros tipos de entidades "vacuosas", como o conjunto vazio, o zero aritmético, e a pausa na linguagem verbal.

Palavras-chave: Não-ser; ontologia de entidades musicais; expressividade.

\footnotetext{
* Guido Imaguire, graduado e doutorado pela universidade de Munique; atualmente é professor no departamento de filosofia da UFRJ e pesquisador do CNPq. Sua principal área de pesquisa é a filosofia da lógica e da matemática, filosofia da linguagem e metafísica. Ele publicou Russells Frühphilosophie: Propositionen, Realismus und die Sprachontologische Wende (2001), On Denoting 1905-2005 (2005), Untersuchungen zur Ontologie (2006), Estudos em Filosofia da Linguagem (2008), dentre outros livros e artigos.
} 
O não-ser sempre foi motivo para perplexidade na filosofia. O pensamento clássico parecia ser incapaz de incorporar o nada, o ente não existente, ao domínio do racional. Para alguns, isso não surpreende, nem constitui propriamente um problema, já que o não-ser, a rigor, não é, e sendo assim, não pode mesmo ocupar algum lugar na nossa estrutura racional do mundo. O que não é não está em lugar algum. E, dito trivialmente, dizer que o não-ser é um problema é o mesmo que dizer que não há problema. ${ }^{1}$

Na filosofia da música, e este é nosso tema aqui, o problema do não-ser emerge na noção da pausa. O que é, exatamente, uma pausa? A música é fundamentalmente um evento acústico complexo esteticamente intencionado e composto de tons simultâneos e subsequentes, com diferentes alturas, durações e timbres. O silêncio intencionado num determinado intervalo de tempo em meio ao fluxo de tons parece ser um caso de não-ser, uma lacuna do ser em meio à racionalidade totalmente preenchida dos sons. Não se pretende fazer aqui uma análise lógico-analítica no sentido rigoroso da palavra. Procurarei, antes, utilizar recursos especulativos e de analogia para derivação e explicitação da natureza, da função e do estatuto ontológico da pausa.

\section{Sobre o nada absoluto da metafísica}

Antes de nos concentrarmos no caso particular da pausa musical, vejamos algumas estações do pensamento ocidental na sua tentativa de integrar o nada ao projeto filosófico de compreensão total da realidade. Já antes da introdução de elementos teológicos cristãos na filosofia durante o período medieval, o não-ser constituía elemento de perplexidade. Aristóteles defendia uma ontologia do

1 Este texto foi apresentado no Colóquio Música \& Filosofia, organizado pelo Departamento de Música de Ribeirão Preto da ECA-USP e ADEMUS (Associação de Amigos do Departamento de Música de Ribeirão Preto), e realizado nos dias 16 e 17 de novembro de 2007. O autor agradece aos participantes pelos valiosos comentários recebidos, em particular pelas observações do Prof. Rodolfo Coelho de Souza. 
pleno, contrário a Leucipo e Demócrito. Grosso modo, a discussão girava em torno da possibilidade do movimento: para Leucipo e Demócrito só com vácuo seria possível haver movimento, pois se o espaço fosse plenamente ocupado, nada poderia sair do lugar. Contra isso, Aristóteles usa o argumento do turbilhão de água: havendo movimento simultâneo de várias partes, não há nenhuma antinomia em se pensar movimento num espaço completamente preenchido. Para Aristóteles vale, pelo contrário, que o absoluto vazio tornaria o movimento impossível, posto que o vazio implica repouso necessário, já que todo movimento é sempre relativo a algum ser, e no vácuo não há ser (v. Schuback, 2007, p. 83).

O horror vacui medieval dá continuidade a essa tradição Aristotélica, adicionando novos elementos de cunho teológico. Como tudo o que existe foi criado por Deus, nada que existe pode ser ruim - afinal, um Ser absolutamente bom não criaria algo ruim. Se algo não existe, então porque certamente não era digno de existência. Nisso se baseia inclusive uma estratégia clássica para se resolver o problema da teodiceia: o problema da compatibilização do fato de que existe mal no mundo, com a ideia de um ser que tudo criou e que é sumamente bom. Segundo a estratégia de despotencialização, o mal, a rigor, não existe. Nada que existe é mal. O mal é simplesmente ausência de ser: a morte é ausência de vida, a ignorância é ausência de saber, a doença é ausência de saúde etc. Tudo o que Deus criou é bom, e tudo o que é bom foi criado.

A superioridade do Ser em relação ao Não-ser permanece como princípio metafísico na modernidade. Em Descartes, esse princípio assume uma dimensão epistemológica. Depois de provar a existência do eu pensante e de Deus, restava a ele demonstrar a existência do mundo exterior. A sua saída foi apelar à bondade de Deus: como Ele é bom, ele não pode querer que nos enganemos constantemente com nossos sentidos. Assim, quando pensamos perceber um Ser, este certamente existe. Ou seja, a bondade divina é garantia epistêmica do Ser percebido. Em Leibniz, a conexão íntima entre o Bem e o Ser é mais ontológica, e se concretiza no ato de criação: do conjunto de infinitos mundos possíveis, Deus escolhe apenas o melhor para criar. Assim, em Leibniz o Bem é o critério de existência. Vale lembrar, é claro, que para Leibniz a melhor totalidade (o melhor 
mundo possível) não é um no qual cada parte é a melhor possível, o que explicaria de modo bastante elegante a existência do mal no mundo. Numa metáfora musical: a mais bela obra musical não é uma constituída por plena harmonia, mas uma que contenha também dissonâncias e tensões.

Observando toda esta longa tradição, Heidegger concebe na contemporaneidade a história da metafísica no Ocidente como uma fuga do nada. A ontologia tradicional simplesmente não tinha categorias para pensar ou lidar com o nada. E, de fato, apesar de todo desenvolvimento da lógica e filosofia da linguagem durante o último século, o nada continua gerando algumas perplexidades, embora muitas, de fato, tenham sido definitivamente superadas.

Na lógica de predicados de primeira ordem na sua versão standard, o seguinte raciocínio é válido: se João procura a fonte da juventude, então existe algo que João procura, logo existe a fonte da juventude. Essa conclusão, no entanto, é obviamente contraintuitiva. E se dissermos que a fonte da juventude não existe, teríamos que concluir que João não procura nada, o que, intuitivamente, não é o caso. Para resolver esse dilema, lógicos têm criado lógicas alternativas (por exemplo, a lógica intensional de E. Zalta). Um problema análogo surge na semântica. Quando se diz

Lula é brasileiro

o sujeito da sentença - "Lula” - é uma expressão que se refere a uma entidade real, um Ser, e lhe atribui a propriedade de ser brasileiro. Mas qual poderia ser a referência do sujeito da seguinte sentença:

Sherlock Holmes era um detetive

Qual Ser corresponde ao sujeito gramatical desta sentença? A propriedade de ser detetive não está sendo atribuída à expressão linguística (a expressão, em si, é uma simples entidade linguística, uma composição de letras). Também não 
podemos identificar Sherlock Holmes com uma ideia na nossa mente, pois uma ideia não é um detetive. Além do mais, a sentença

Sherlock Holmes não existe

é, no sentido mais usual, uma sentença verdadeira. Se a referência de "Sherlock Holmes" fosse minha (ou nossa) ideia, um simples evento ou estado mental, a sentença não seria verdadeira, mas falsa, pois a ideia existe. E quando digo que “Lula é brasileiro”, não pretendo dizer que minha ideia de Lula é brasileira, o que indica que, numa interpretação normal, o sujeito da sentença é usado de modo referencial: procura-se falar sobre o objeto denotado pela expressão.

A suposição de que não existe uma referência para certas expressões da linguagem - o problema da lacuna referencial - nos remete novamente à questão: mas então sobre o que falamos, quando dizemos que Sherlock Holmes não existe? Se não falamos sobre nada, então a frase não teria sentido, ou todas as frases semelhantes ("Saci não existe", "Papai Noel não existe” etc.) diriam o mesmo, já que atribuem não existência ao nada. Mas isso parece insustentável, já que cada uma destas frases diz algo diferente.

Claro que soluções bastante razoáveis foram apresentadas no domínio da filosofia analítica da linguagem. A referência a entidades não existentes, do ponto de vista semântico, permite algumas soluções interessantes: como a distinção de sentido e referência de Frege (Über Sinn und Bedeutung, 1982), ou a teoria das descrições de Russell (On Denoting, 1905). Mas assim como a ontologia não pode ser completamente reduzida à semântica, assim também o problema ontológico não pode ser considerado definitivamente solucionado, mesmo porque não existe consenso sobre qual das estratégias de solução para o problema da vacuidade referencial é a mais adequada.

Embora essa breve introdução histórica seja extremamente panorâmica e superficial, ela já nos permite extrair alguns elementos sistemáticos para uma primeira aproximação negativa do problema da pausa musical. Ou seja, podemos inicialmente excluir o que não está em jogo na nossa investigação sobre a pausa. 
Em primeiro lugar vale destacar que o verdadeiro objeto do horror metafísico era o absoluto nada, ou seja, a absoluta ausência de qualquer realidade ou determinação. O absoluto nada metafísico é isento de qualquer propriedade ou característica - nas palavras dos medievais: nihili nullae sunt proprietates $^{2}$ - logo, não há nada a ser dito sobre ele. A pausa musical, no entanto, não é um caso de absoluto não-ser: toda pausa musical tem algumas propriedades mínimas, e não pode, portanto, ser um puro nada. Grosso modo, uma obra musical pode ser caracterizada como um complexo temporalmente estruturado de notas, e cada nota, por sua vez, poderia ser concebida como feixe de certas propriedades acústicas como altura, duração, volume e timbre. Toda pausa tem, no mínimo, a propriedade intrínseca (absoluta ou não relacional) da duração e a propriedade relacional da sua posição na sequência temporal dos tons na qual está inserida. Uma pausa não é, portanto, um caso de absoluta vacuidade e indeterminação. Aliás, a identificação de cada nota a partir deste quádruplo de propriedades - altura, duração, volume e timbre - abre espaço para a possibilidade de se conceber a pausa como instanciando as propriedades de altura e timbre. Não há nada de ilógico ou contraditório na concepção da pausa como uma nota, com altura, duração, timbre, mas com o volume zero

36 (onde ainda permanece a questão se volume zero significa o mesmo que ausência de volume). Uma determinada pausa pode ser um dó "executado" com volume "zero" (executada de modo "ultrapianíssimo"); uma outra pausa, um "ré" com volume zero. Talvez possamos distinguir uma pausa "tonal" (com altura e volume zero) de uma pausa "atonal" (a simples ausência de tonalidade), de acordo com a função da pausa particular e sua função no todo da frase musical onde ocorre. De fato, mais adiante defenderei a necessidade da existência da "pausa legítima" ou "atonal". Também se poderia admitir que certas pausas tenham um determinado timbre. Considere, por exemplo, uma peça para piano e flauta: uma pausa na linha da flauta deve ser concebida como uma pausa com o timbre da flauta, e não do piano. Dito positivamente, a pausa não é mero não-ser, a pausa não é

\footnotetext{
${ }^{2} \mathrm{O}$ nada não tem propriedades (v. Angelelli, 2006).
} 
ausência de som. A pausa não só é real, como ela existe intencionalmente (tão intencionalmente quanto a vírgula em uma sentença).

Disso podemos extrair um segundo aspecto relevante. Parece-me claro que a dimensão ética precisa ser excluída da nossa investigação sobre a pausa. Do ponto de vista teológico e metafísico, de fato, podemos admitir a possibilidade de identificar o Ser com o Bem, e o Não-ser com algo eticamente deficiente. Trata-se de uma questão difícil e aberta. Mas como já concluímos que a pausa não é um caso de não-ser, na medida em que a pausa instancia uma série de propriedades, exclui-se sua conexão com o mal ético ou metafísico. Permanece, claro, a questão de como conceber a função e o valor da pausa musical, que será em breve nosso tema.

Em terceiro lugar, da discussão na Antiguidade entre Aristóteles e Leucipo e Demócrito podemos extrair a seguinte lição: não é o caso que a pausa é condição de possibilidade do movimento musical, da sequência "preenchida" de tons, nem vice versa. Não há nada de antinômico na concepção de uma obra musical sem pausas, inclusive numa eterna sequência de tons, nem de uma obra musical composta exclusivamente de silêncio, como na obra 4'33" de John Cage. Argumentos de mútua dependência ontológica (só pode existir noite porque existe dia, só pode existir luz porque existe escuridão etc.), frequentemente usados na tradição filosófica para explicar a necessidade do nada, se mostraram inócuos recursos retóricos, extremamente frágeis em sua generalização. Não existe matéria porque existe antimatéria, nem existe universal autoidentidade porque existem objetos que são "autodiferentes". Nem mesmo há uma necessidade epistemológica. Não precisamos da noção de antimatéria para entender o que é a matéria, nem precisamos da noção de repouso para entender o que é movimento. Em suma, a pausa ou o silêncio não é condição de possibilidade do som, em toda sua variação tonal, nem vice-versa. Disso não se deriva, claro, que a pausa não tenha valor perceptual ou estético na sequência sonora na qual se insere. Assim como um orifício num corpo físico pode ser considerado simples ausência indesejada de matéria, como um furo na camisa, alguém poderia tentar pensar a pausa como uma espécie de "furo" na sequência de sons. Mas esses orifícios materiais não são sempre uma simples carência 
indesejada ou não intencionada de matéria. Eles podem ser intencionados e essenciais, assim como o são os orifícios de uma peneira. A questão é, sempre, entender sua função, seu papel. E é justamente a tentativa de compreensão da função da pausa que nos ocupará no resto deste artigo.

\section{Da dimensão biológica da pausa}

A pausa - agora no sentido geral, não particular musical - é certamente uma necessidade biológica humana, e aparentemente presente, de uma ou outra forma, em qualquer forma de vida, das mais complexas às mais elementares. Embora não haja pausa metabólica completa e o sono seja apenas uma interrupção do fluxo consciente de percepção (o que, obviamente, não significa pausa da maioria das funções cerebrais), um estado de vigília ininterrupta prolongada seria não somente prejudicial, mas até mesmo letal. O estado de inconsciência induzido na anestesia durante uma cirurgia não tem apenas a função de nos poupar da sensação desagradável da dor, mas mesmo de preservação da vida. A necessidade biológica reflete a estruturação das atividades sociais. Todas as atividades sociais humanas são intermeadas e estruturadas por momentos de pausa: do fim de semana às férias anuais, do jogo de futebol ao congresso científico. Do ponto de vista biológico, a pausa tem o sentido ou a função de regeneração. Mesmo a Deus é atribuído um dia de descanso no relato bíblico da criação, o que parece ser, claro, mais uma antropomorfização do que um relato com pretensão de fidelidade.

Certamente a pausa musical tem, dentre outras, também uma função regenerativa. No fluxo do evento acústico, a pausa representa o momento de respiração e regeneração, tanto do intérprete como do ouvinte. Mais propriamente, dever-se-ia distinguir entre diferentes tipos de pausa, que assumem diferentes funções. Em particular, deve-se distinguir uma pausa interna a uma frase melódica e uma pausa que separa diferentes frases ou movimentos de uma obra. Embora esse segundo tipo de pausa tenha realmente, via de regra, a função de regeneração parcial - e não descanso final, assim como o sono não é 
a morte -, o primeiro tipo pode tanto codificar regeneração como, pelo contrário, acúmulo de tensão. Uma pausa antes da resolução harmônica ou melódica definitiva sugere um momento de concentração de forças para o prosseguimento da busca pelo alvo final.

Mas a regeneração é apenas uma dentre várias outras funções, e provavelmente nem a mais fundamental. Essa função se torna necessária quando se toma a música como um evento real, concreto, no espaço e tempo, realizado por seres humanos com capacidades físicas limitadas. Como já constatamos acima, se tomarmos a música do ponto de vista puramente abstrato e formal, como um complexo estruturado de propriedades acústicas e rítmicas, constatamos que não há nada de antinômico na noção de uma obra completamente sem pausas, inclusive sem início e sem fim. Significa isso que, no domínio formalabstrato, não existem entidades análogas à pausa?

\section{Da pausa formal: o zero, o conjunto vazio e o ponto}

A resposta à última questão é um claro "não". Se por "pausa" se compreende uma entidade essencialmente temporal (no sentido de "interrupção temporal"), então é óbvio que não pode haver pausa em estruturas formais pelo simples e trivial fato de que estruturas formais, como a aritmética e a geometria, são essencialmente atemporais. Mas, como a análise ontológica inicial mostrou, a pausa pode ser concebida tanto como interrupção do fluxo de tons, quanto como uma nota com altura determinada, mas volume zero. Isso nos abre as portas para a compreensão de uma nova caracterização, agora formal, da pausa. A pausa musical está para a música como o zero para a aritmética, o conjunto vazio para a teoria de conjuntos, e o ponto para a geometria.

O ponto geométrico, a figura de extensão nula, tem a admirável propriedade de codificar uma espécie de não-ser espacial, e, ao mesmo tempo, ser a base constitutiva de absolutamente tudo que possa existir espacialmente. Uma reta nada mais é que um conjunto de (infinitos) pontos. Mas como a reta pode ter um comprimento, se ela é a mera soma de elementos com comprimento 
igual à zero? Mesmo a soma de infinitos zeros tem como resultado zero. Também o plano, com extensão infinita, nada mais é do que o conjunto desses elementos com extensão zero. Finalmente, o espaço tridimensional, em toda sua extensão, e corpos com volume no espaço nada mais são do que um conjunto de infinitos pontos, isto é, de elementos com volume zero. Raciocínios análogos valem tanto para o zero na aritmética, como para o conjunto vazio na teoria de conjuntos. $\mathrm{Na}$ axiomatização da aritmética de Peano, o zero entra como único elemento primitivo, do qual todos os outros números são gerados pela relação de sucessor: o 1 nada mais é que o sucessor do zero, e o 2 o sucessor do sucessor do zero etc. Todas as propriedades aritméticas elementares são então, com auxílio de cinco axiomas, derivados dessa estrutura formal. Na teoria de conjuntos "pura" (que exclui quaisquer objetos que não sejam conjuntos), o conjunto vazio forma, analogamente, a base indutiva da qual se gera toda a hierarquia de infinitos conjuntos.

Não vejo de que maneira se poderia conceber a composição de toda estrutura tonal a partir da pausa. Neste sentido, a pausa não é elemento constitutivo da estrutura acústica, como o ponto do espaço. Além do mais, a pausa não é o elemento de zero extensão temporal, como o instante temporal mínimo. Pelo contrário, uma pausa só é uma pausa na medida em que tem uma 40 extensão temporal. Mas outras interessantes analogias podem ser extraídas. A primeira se refere à independência ontológica. Na ontologia da matemática se considera em geral que os conjuntos são ontologicamente dependentes de seus membros; apenas o conjunto vazio, justamente por não conter elementos, é ontologicamente primário e independente. Também na aritmética de Peano, como os números são gerados a partir da relação de sucessão a partir do zero, eles dependem do zero, que é, por sua vez, primitivo e independente. Assim, enquanto todos os tons são ontologicamente dependentes da matéria (não há som no vácuo), a pausa é ontologicamente independente de qualquer materialidade.

A segunda analogia concerne ao seu caráter contextual. O ponto geométrico, apesar da extensionalidade nula, é, ainda assim, uma entidade espacial, definida justamente pelas suas propriedades espaciais, mais exatamente, pela sua posição no espaço total. Cada ponto é diferente de outro ponto. Mas 
abstraindo de sua posição, todos os pontos são exatamente iguais. Ou seja, apenas a posição individua cada ponto. A situação é, aliás, ainda mais radical na teoria de conjuntos. Como cada conjunto é definido exclusivamente pelos seus elementos, "todos" os conjuntos vazios são, a rigor, um só conjunto vazio. O conjunto dos elefantes voadores é exatamente o mesmo conjunto dos cavalos azuis. Mas disso não se extrai que o conjunto vazio não seja um conjunto com propriedades lógicas como qualquer outro conjunto. Assim, igualmente, na medida em que a pausa musical tem propriedades - ela tem, no mínimo, como vimos, uma duração e uma posição - ela não é nada. Somente o nada não tem propriedades. Mais exatamente: tudo o que é, é de alguma forma, tem propriedades, e tudo que tem propriedades é, existe.

Mas que a pausa não é um não-ser, isso já foi destacado no início. A nova lição que podemos derivar da análise das estruturas formais é que, em todos esses casos, o elemento "mínimo" (para dar um nome provisório comum para o ponto, o conjunto vazio e o zero) é definido plena e exclusivamente pela sua posição na estrutura total. Cada ponto é definido pela sua posição espacial (por exemplo, pelas coordenadas x e y no ponto cartesiano), o zero pela sua posição na série de sucessores (é dessa posição que ele deriva todas as suas propriedades aritméticas), e o conjunto vazio pela posição na estrutura hierárquica de todos os conjuntos. A conclusão similar para a pausa musical parece ser, então, que a característica essencial e individuadora de cada pausa é sua posição na estrutura global. Tomadas por si só, isto é, isoladas do contexto musical particular em que ocorrem, todas as pausas são iguais. A individuação da pausa é definida plena e exclusivamente pela posição que ela ocupa na sequência total dos sons (assim como duas moléculas de água completamente similares em todas as suas propriedades intrínsecas são plenamente individuadas pelas diferentes posições que ocupam no espaço).

Especulamos acima sobre a possibilidade de concebermos a pausa (ou alguns casos de pausa) como exemplificando a propriedade de altura e timbre. A dificuldade disso consiste basicamente na inteligibilidade da função de um tom "executado" com volume zero. Absolutamente certo, por outro lado, é o fato de 
que toda e qualquer pausa instancia as propriedades de duração e posição. A partir disso penso poder concluir que a função primordial da pausa é justamente derivada desta sua propriedade identificadora. Para compreender melhor essa função, no entanto, mais uma analogia será útil, a saber, a com a linguagem verbal.

\section{Pausa como recurso de expressividade}

De todas as analogias possíveis, a analogia mais adequada para a música é a da linguagem verbal. Uma obra musical pode ser trivialmente comparada a um texto, inclusive devido à sua estrutura linear (unidimensional). Uma sinfonia seria o livro e os movimentos os capítulos, divididos em parágrafos e frases. A pausa, a pontuação, é um elemento constitutivo necessário de toda e qualquer linguagem. Não há linguagem sem pausa, embora alguns sistemas notacionais antigos carecessem de sinais de pontuação, como o hebraico. Nesses casos, a pontuação era "deduzida e lida".

Compreender a pausa na linguagem pode nos ajudar a compreender a pausa musical. Segundo o princípio semântico de composicionalidade, o significado de uma frase é uma composição do significado das palavras que

42 compõem a frase. O que essa formulação padrão parece esquecer, no entanto, é que não apenas as palavras ou expressões são determinantes para o significado da frase, também a pontuação - as pausas - o são. Para recordar um exemplo famoso, veja a seguinte sequência de palavras:

Deixo os meus bens a minha irmã não a meu sobrinho jamais será paga a conta do alfaiate nada aos pobres.

O problema dessa sequência de palavras é que ela não determina univocamente uma frase com um significado. Trata-se de uma sequência ambígua, da qual podemos extrair diferentes significados de acordo com as diferentes posições e tipos de pontuações que inserirmos: 
(1) Deixo os meus bens a minha irmã. Não a meu sobrinho. Jamais será paga a conta do alfaiate. Nada aos pobres.

(2) Deixo os meus bens a minha irmã? Não. A meu sobrinho. Jamais será paga a conta do alfaiate. Nada aos pobres.

(3) Deixo os meus bens a minha irmã? Não. A meu sobrinho? Jamais. Será paga a conta do alfaiate. Nada aos pobres.

(4) Deixo os bens a minha irmã? Não. A meu sobrinho? Jamais. Será paga a conta do alfaiate? Nada. Aos pobres.

(5) Deixo os meus bens? Não a minha irmã e a meu sobrinho. Jamais será paga a conta do alfaiate. Nada aos pobres.

Diferentes distribuições de pontuação geram, assim, diferentes frases logicamente incompatíveis entre si. Poder-se-ia objetar contra a analogia da pausa com a pontuação que no caso da linguagem verbal temos diferentes tipos de sinais de pontuação: o ponto, a vírgula, a interrogação e a exclamação, enquanto a pausa musical é um tipo único de pontuação. Penso, no entanto, que tal objeção ignora o fato de que apesar de haver uma única forma de silêncio, as diferentes posições que a pausa ocupa, por exemplo, dentro de um determinado compasso, e a sequência tonal imediatamente anterior à pausa geram diferentes efeitos que podem ser comparados às diferentes funções da pontuação verbal. Além disso, o silêncio da articulação verbal também é, a rigor, único e invariante. As diferentes variações de pontuação se devem às diferenças de extensão da pausa e, mais ainda, ao tipo de acentuação melódica dos sons anteriores à pausa. Assim, de fato, o caso da pausa musical me parece ser exatamente análogo ao da pontuação. Assim como a pontuação é condição de possibilidade de alguns significados (sem a pontuação não teríamos os vários significados expressos nas frases acima), assim também a pausa é condição de possibilidade de um conjunto infinito de frases musicais (a infinitude desse conjunto pode ser demonstrado por simples análise combinatória).

Dessa forma, abdicar da pausa significaria abdicar do recurso primordial de estabelecimento de significado musical. Constatamos acima que não há nada de antinômico na noção de obras musicais sem pausa. Mas sem a pausa, a música 
sofreria uma enorme restrição no seu potencial expressivo. Se reconhecermos que uma das dimensões ou tarefas fundamentais de toda e qualquer manifestação artística consiste na expressão de algum "conteúdo" (no sentido mais extenso e indefinido possível dessa palavra), e que um de seus princípios regulativos principais é o rompimento com demarcações e limitações, uma restrição da expressividade como a abdicação da pausa significaria limitar a música a sua forma de arte - empobrecimento imperdoável para a música como arte. Claro que abdicar de qualquer tom (digamos, por exemplo, abdicar da nota "dó" no sistema tonal ocidental) significaria uma restrição do potencial expressivo da música. Mas a pausa tem uma função estruturante, semelhante à pontuação linguística, e diferente de qualquer outra entidade musical, de modo que o seu papel é ainda mais universal. Aliás, essa função estruturante se deve justamente à sua natureza atonal - disso se derivaria, afinal, a necessidade de se aceitar uma pausa que não seja simplesmente uma nota executada com volume zero. Uma pausa estruturante não é um tom qualquer executado em "ultrapianíssimo", assim como uma vírgula ou um ponto não é uma palavra pronunciada com volume zero.

\section{Referências}

ANGELELLI, I. The interpretation of nihili nullae sunt proprietates. In: IMAGUIRE, G. \& SCHNEIDER, C. Untersuchungen zur Ontologie. Philosophia Verlag: München, 2006.

FREGE, G. Über Sinn und Bedeutung [1892]. In: . Funktion, Begriff, Bedeutung. 7 Auflage. Göttingen: Vandenhoeck \& Ruprecht, 1994. Artigo republicado na coletância de textos.

RUSSELL, B. On Denoting [OD] [1905]. Reimpresso. In: B. Russell. Logic and Knowledge. London: George Allen and Unwin, 1956. p. 42-56.

SCHUBACK, M. S. C. O vazio do nada - Heidegger e a questão da superação da metafísica. In: IMAGUIRE, G. \& OLIVEIRA, M. \& ALMEIDA, C. Metafísica Contemporânea. Petrópolis: Vozes, 2007.

E-mail: guido_imaguire@yahoo.com

Artigo recebido e aprovado em 14 de novembro de 2009 